\title{
A Review on the Phenomenon of Interpersonal Dependency
}

\section{Kişilerarası Bağımlılık Fenomeni Üzerine Bir Derleme}

\author{
Tubanur Çelik İskifoğlu¹, Gökhan İskifoğlu²
}

\begin{abstract}
:
The basic purpose of the current research study is to conduct a review on interpersonal dependency, which is considered in behavioral dependency as a subdivision of the general subject of dependency. Within the main frame of this subject, the secondary aim is to take attention on the interpersonal dependency which was not frequently studied in our culture. Regarding this purpose, this review study has put a great emphasis on explanations and interpretations with respect to strategies to cope with dependency in relation to the types of dependency. According to the specified notion, interpersonal dependency is only a sort of dependency categorized under the general notion of dependency, which was not studied well enough in the literature of Turkish context. Individuals who suffer from interpersonal dependency usually believe that this is their fate and they prefer to live with that in order to get professional support, which, in turn, make life harder both for themselves and for significant others in their lives. For that reason, the effect of Cognitive Behavioral Therapy was also reviewed to bring deeper insight into possible precautions to prevent individuals from the negative effects of interpersonal dependency.
\end{abstract}

Key Words: Dependency, Behavioral Dependency, Interpersonal Dependency, Cognitive Behavioral Therapy.

${ }^{1}$ MSc., Guide and Psychological Counselor, Cyprus Social Sciences University, Orcid İd: https://orcid.org/ 0000-0002-7661205X

${ }^{2}$ Assist. Prof. Dr. European University of Lefke, Turkish Republic of Northern Cyprus, Orcid İ: https://orcid.org/ 00000001-8119-4254

Address of Correspondence/Yazışma Adresi: Cyprus Social Sciences University Department of Guidance and Psychological Counseling, Haspolat, Cyprus, E-mail: tubanur.celik@ kisbu.edu.tr

Date of Received/Geliş Tarihi: 10.06.2020, Date of Revision/Düzeltme Tarihi: 06.08.2020, Date of Acceptance/Kabul Tarihi: 10.06.2020, Date of Online Publication/Çevirimiçi Yayın Tarihi: 27.08.2020

Citing/Referans Gösterimi: Çelik İskifoğlu, T., İskifoğlu, G. (2020). A Review on the Phenomenon of Interpersonal Dependency, Cyprus Turkish Journal of Psychiatry \& Psychology, 2(3): 187-91.

(C) 2020 The Author(s). Published by Cyprus Mental Health Institute / Cyprus Turkish Journal of Psychiatry and Psychology (www. ktppdergisi.com). This article is an open access article distributed under the terms and conditions of the Creative Commons Attribution 4.0 license which permits use, sharing, adaptation, distribution and reproduction in any medium or format, provided the original work is properly cited and is not used for commercial purposes. http://creativecommons.org/licenses/by/4.0/ 


\section{Özet:}

Bu çalışmanın amacı; bağımlılığın alt türü olan davranışsal bağımlılığın içinde yer alan insana bağımlılık konusuyla ilgili bir derleme yapmak ve ilgili literatüre hem katkı sağlamak hem de hakkında özellikle ülkemizde çok az yayın bulunan bu konuya dikkat çekmektir. Bu sebeple; bağımlılık ve bağımlılık çeşitleri ve bu tanımlamalardan elde edilen sonuçlara bağlı kalarak nedenleri ve başa çıkma yöntemleri ile ilgili literatür destekli açıklamalara yer verilmiştir. Buna göre; insana bağımlılık, bağımlılığın altında bulunan türlerden sadece biridir. Toplumumuzda oldukça diğer bağımlılık türleri kadar yaygın olmakla birlikte Türk alan yazınında fazla yer almamaktadır. Toplumumuzda insana bağımlı olan çoğu insan bu durumu kabul edip ve tedavi olmak yerine bu durumun kaderleri olduğuna inanır ve bu şekilde yaşamaya çalışarak hem kendilerini hem de çevresindeki bağımlı oldukları kişilerin hayatını zorlaştırırlar. Kişilerarası bağımlılığın tedavisi bağlamında önlem alınması adına Bilişsel Davranış̧̧ı Terapinin etkilerinin incelendiği çalışmalara da yer verilmiştir.

Anahtar Kelimeler: Bağımlılık, Davranışsal Bağımlılık, İnsana Bağımlılık, Bilişsel Davranışçı Terapi.

\section{Giriş}

Bağımlılık; bugünlerde birçok kişinin bildiği veya bir şekilde duyduğu bir kavram olarak karşımıza çıkmasına karşın bağımlılığın bir alt türü olan davranışsal bağımlılı̆̆ın içinde yer alan insana bağımlılık ise hakkında çok az şey bildiğimiz bir durumudur (Diclemente, 2016). Diğer bağımlılık türleri gibi ergenlik döneminde ortaya çıkan birçok kişinin zarar gördüğü bu olgunun tam olarak ne olduğu, hangi değişkenlerin etkisi altında kalarak oluştuğu, nasıl anlaşılacağı ve ne tür tedavi önlemleri alınacağı ile ilgili araştırmaların az olduğunu görmekteyiz.

İnsana bağımlılık, bilhassa içinde yaşadığımız toplumda, birçok bozuklukla eş tanılanabilir. Tabii ki, çalışılan bu konuyla alakalı olarak hali hazırda yürütülmüş araştırmalar alan yazın içerisinde derli toplu değildir ve konu ile ilgili bu dağınıklıktan dolayı araştırmacılar kişiye bağımlılık fenomeni hakkında yeni araştırmalar desenleme firsatı bulamamış olabilirler (Ançel ve Kabakçı 2009).

$\mathrm{Bu}$ açıklamalar 1şı̆̆ında ve bahsi geçen eksiklik dikkate alındığında, bu çalışmanın amacı; Türkiye'de, KKTC'de ve dünyada yapılmış çalışmaları mercek altına alıp kişiye bağımlılık fenomeninin aslında ne olduğunu, nasıl evrildiğini, çalışma mekanizmasının ve uyarıcılarının neler olabileceğini, nasıl anlaşılacağını ve tedavi girişimlerindeki güncel olanakların hangileri olabileceğini derleyerek ortaya koymaktır.

\section{Bağımlılık, Davranışsal Bağımlılık, İnsana Bağımlılık}

İnsana bağımlılı̆̆ tam olarak anlayabilmek için bağımlılı̆̆ tam olarak anlamak gerekmektedir (Bornstein, 1992). Bağımlllık hem psikolojik hem biyolojik hem de sosyal olarak kişiyi etkileyen bir durumdur. Bu konu ile ilgili yapılan çalışmalar artarak devam etmesine rağmen bağımlılık da artarak devam etmektedir (Ainsworth, 1972; Ulusoy, 2010). Sonunda ödül alınan her şeye kişi bağımlılık geliştirebilir (Havaçeliği, 2013). Son yıllarda yapılan bilimsel çalışmalara göre sadece uyuşturucu, alkol, tütün gibi dışarıdan alınan maddeleri içermeyen bağımlılıklarda da zorlayıcı ve işlevsiz şekilde davranılabileceği kanısına varılmıştır (Aydın, 2016). Diğer yandan, alkol, uyuşturucu veya tütün kullanımı gibi bireye ve topluma zararlı etkileri olan bağımlılıklar gibi davranışsal bağımlılıklar da toplumda ve bireyin iș, aile hayatında hem ekonomik hem de kişilerarası iletişim ve etkileşim bağlamında da ciddi olumsuz etkilere yol açtığı gözlemlenmiştir (Baykan, 2014). İnsanların kendi çabalarıyla baş edemedikleri ihtiyaçları karşılama özelliği vardır. İstemli davranışın zorlantılı davranışa dönüşmesiyle karakterize olan bu hastalığın temeldeki yapısal işlevi beyindeki nöro-kimyasal tepkimelerle meydana gelmektedir. Hem genetik hem de çevresel etkenler bir araya geldiğinde bağımlılık tablosu oluşabilir. Ciddi psikolojik ve bedensel problemlerin eşlik ettiği bu hastalıkta bağımlılık temel nedendir. Bağımlı kişinin davranışı bağımlı olduğu duruma, nesneye, olaya köleleşmeye doğru gider (Sümer, Oruçlular, Çapar, 2015). Aynı zamanda bağımlılık bir aile hastalığı olarak da kabul edilebilir. Çünkü tüm aile bireylerini de etkiler ve ilgilendirir (Kökçü ve Kesebir, 2010). Öyle ki kişinin iş, aile, toplumsal ilişkiler ve bir çok beşeri ilişkisini tehdit ederek tehlikeye sevk eden bu durum kişinin bir çok suça eğilim göstermesini de beraberinde getirmektedir (Ançel, 2012). Bağımlılığın yaş, etnik köken, kültür, din ve felsefi bakış açılarından bağımsız olarak toplumun her kesimindeki insanı sosyalkültürel yapısı fark etmeksizin etkilediği vurgulanmaktadır (Tarhan ve Nurmedow, 2019). Bağımlı kişilerin eğilimli olduğu bir diğer davranış şekli ise kendilerine ters düşerek kendi inanç, değer ve ahlak anlayışlarından ödün vermek gibi karşımıza çıkmaktadır. İstemek ve rahatlama, uzun vadeli negatif etkisi ve bırakmakta zorluk varsa, bir bağımlılık söz konusudur. (Ainsworth, 1972). Bağımlılık bir tercih değil duygusal acıya verilen bir tepkidir. Çünkü, yapılan çalışmaların birçoğu bağımlılı̆̆ın altında yatan faktörün altında travmanın yattığı yönünde bir inanç vardır (Sümer, Oruçlular, Çapar, 2015). Depresyon, madde ve alkol ile ilişkili bozukluklar, dikkat eksikliği hiperaktivite bozukluğu, kişilik bozuklukları bağımlılığa sıklıkla eşlik eden psikiyatrik bozukluklardır (Bornstein, 2005).

\section{Bağımlılık ve Beyin}

Bağımlılık; son yıllarda aşırı artış göstererek sağlık sorunları içerisinde en çok rastlanılan problemlerden biri olarak literatüre geçmiştir (Carlson, 2014; Tarhan ve Nurmedov, 2019). Beynin istemli olarak kontrol edilemeyen alanlarında oluşur. İrade unsurunun devreye 
girmesi için kişinin iyileşmek istemesi şarttır (Diclemente, 2016). Beynin her bir aşaması bağımlılıktan olumsuz olarak etkilenmektedir. Cinsellik, yemek, su kişilerin doğal haz kaynaklarıdır. Bağımlı olunan durum ya da madde beynin ödül merkezinden (ventral tegmental alan) yüksek miktarda dopamin salgilamasına neden olur (Carlson, 2014). Bu salınım zaman içerisinde beynin muhakeme, karar vermeden sorumlu olan frontal korteksi etkileyerek yanlış karar almasına, alınan kararların bağımlılık yapan madde ya da durum yönünde olmasına neden olmaktadır. Aynı zamanda, yeni bilgiyi öğrenme, kaydetme ya da hatırlama yetilerinde de bozulmalar meydana gelir (Tarhan ve Nurmedov, 2019).

\section{Kişiye Bağımlılık}

Tanım olarak kişiye bağımlılık; yakınlık kurma ve etkileşim ihtiyacı etrafinda dönen kompleks, irrasyonel düşünceler, inançlar, duygular ve davranışlar olarak adlandırılabilir (Wells, Hill, Brack, Brack ve Firestone, 2006). Diğer bağımlılıklarda olduğu gibi insana bağımlılıkta da bir haz ve eksiklikten kaynaklanabileceğini değerlendirmek uygundur (Springer, Britt ve Schlenker, 1998). Genel olarak bağımlılıkta, bağımlı olunan maddenin, olayın, durumun ya da insanın kişilerdeki bir boşluğu doldurduğu, bir eksikliği tamamladığı için vazgeçilmez olduğu ortadadır (Bornstein, 1992). Kişiye bağımlı kişi sevmekten çok sevilmek ister. Bu sebeple, kişi kendi kişiliğini ortadan kaldırarak sürekli onların beklentisi doğrultusunda davranır (Pincus ve Wilson 2001). Kendisini ve çevresindeki kişileri "iyi" insan olduğuna inandırmaya çabalar. İnsanların yardımına koşmak, etrafındaki insanların görüşlerini paylaşmak, kendi isteklerini göz ardı ederek ortaya koymamak ve kendi çıkarlarını öncelemeden yaşama eğilimi içerisine girmek gibi tipik davranışlar sergilerler (Havaçeliği, 2013). Her ne kadar insanlar ondan bahsederken iyi bir insan olduğuna yönelik açıklamalar yapsalar bile bu kişiyi iyi olarak tanımlamak güçtür (Soylu, 2017). Birçoğu geçmişin uslu çocukları olan bu kişiler, çevrelerine sevgi karşı1lı̆̆ rüşvet dağıtırken, kendi kişiliklerinden vazgeçmiş olmanın yarattığı düşmanlık duygularını da sürekli baskı altında tutmak zorunda kalırlar ve böylece bu durumda kendilerine yabancılaşırlar Öyle ki bu kişiler zamanında akıllı ve uslu çocuk olarak bilinen kişiler olmanın yanı sıra çevrelerinden edinecekleri sevgi için kendi kişiliklerinden ödün vermeye hazırdırlar. Ancak bu durumun kendilerini nasıl bir geleceğe sürükleyeceği ile ilgili en ufuk fikirleri dahi yoktur (Bowlby, 1982; Hirschfeld, Klerman, Gough, Bareett ve Korchin, 1977). Çevresindeki kişiler tarafindan onaylanma, desteklenme ya da yardım alma gereksinimlerini karşılanmadığını düşündüğünde reddedildiğini ya da yalnızlığı ile baş edemeyeceğini düşünüp depresyona girebilir (AlonsoArbiol, Shaver ve Yarnoz, 2002; Ulusoy, 2010). Bağıml kişiler gerçekte kendilerini güçsüz ve alçak gönüllü olarak sunarak başkalarının gözüne girmeye çalıştıklarını, pasif ve uysal davrandıklarını, diğer durumlarda (örneğin ilişkinin biteceğine ilişkin korku duyulduğunda) terk edilmemeyi garantilemek için gerekli görülen her yolu kullanarak bir hayli iddialı ve agresif olduklarını belirtmişlerdir (Lancer, 2018). John Bowlby tarafından geliştirilen bağlanma kuramı erken dönemde bakım verenlerle kurulan ilişskilerin kalitesinin kişinin duygu düzenleme becerilerini, yakın ilişkilerdeki beklentilerini ve davranışlarını derinden etkilediğini öne sürmektedir
(Bowlby, 1982). Otoriter, katı, aşırı koruyucu ebeveynlik stilleri bağımlılık düzeyindeki artışla doğru orantılı bulunmuştur. $\mathrm{Bu}$ durumun çocuğun öz-yeterlik hissini etkileyeceği gibi bağımsız davranışların cezalandırılması ve bağımlılı̆̆ın pekiştirilmesi sonucu çocuğun özerklik kazanmasının engelleneceği ve çocukların kendilerini işe yaramaz ve ayrıca yetersiz olarak değerlendirmeyi öğrenecekleri vurgulanmıştır (Arntz, 2012). Bu durumun yanı sıra, çocukluktaki duygusal istismar da yetişkinlikteki bağımlılıkla ilişkilendirilmektedir. Maslow'un ihtiyaçlar hiyerarşisi piramidinin en üst basamağında kendini gerçekleştirme yer almaktadır (Maslow, 1970; İnanç ve Yerlikaya, 2008). Psikolojik danışmada varılması istenilen nihai amaç da danışanın kendini gerçekleştirmesine yardımcı olabilmektir. $\mathrm{Bu}$ koşullardan biri de bireyin kendi başına yetebilmesi, yalnızlığı ile baş edebilmesidir. Yani diğer bir değişle başka bir kişiye bağımlı kalmadan bağımsız olabilmeyi başarabilmesidir. Bireyin kendini gerçekleştirmesi de kendi kapasitesinin ve sınırlarının farkında olarak var olan yeteneklerini en üst düzeyde kullanabilmesinden geçer (Bornstein, Krukonis, Manning, Mastrosimone ve Rossner, 1993). Bağımlı kişilerin toplum içerisindeki uyum sürecinde itaat, boyun eğme gibi sağlıksız yöntemleri daha sık kullanırlar (Yakın, 2014). Bu durum kişiler arası bağımlılığın psikolojik sağlığın bozulmasındaki rolünü belirginleştirir ve depresyon, kaygı, yeme bozuklukları gibi ruh sağlığı bozulmaları ile ilişkilendirilebilir (Dereli, 2018).

\section{Yöntem}

$\mathrm{Bu}$ çalışma nitel araştırma yöntemlerinden biri olan betimsel derleme (tarama) yöntemi ile araştırılmıştır. Nitel araştırma tekniklerinden içerik analizi tekniği kullanılarak toplanan veriler analiz edilmiştir. Calışmanın amacına ve sınırlılıklarına bağlı kalınarak oluşturulan anahtar kelimeler doğrultusunda hangi eserlere ulaşılacağına karar verilmiştir. Bununla birlikte alan yazın taranırken hangi çalışmaların dikkate alınacağı ve hangilerinin eleneceği belirlenmiştir (Hsieh ve Shannon, 2005). Türkiye'deki, KKTC'deki ve dünyadaki alanla ilgili yapılmış çalışmalara ulaşabilmek için kullanılan veri tabanları sırasıyla; Clarivate ajansına bağlı Social Science Citation Index (SSCI), ERIC, TÜBITAK, ULAKBIM ve Google akademik şeklindedir.

Elektronik ortamda yapılan araştırmalara ek olarak KKTC'de bulunan üniversite kütüphaneleri ziyaret edilmiş ve elektronik ortama işlenmemiş olan kitaplar ve tezler araştırılmıştır.

\section{Tedavi Yöntemleri}

Bağımlılık tedavi edilebilir hastalıklardır. Tedavinin kalitesini, süresini ve içeriğini belirlemede etkili olan en önemli faktör kişinin tedavi olmak yönündeki istekliliğidir. Danışmanlık sürecinde, kişiye bağımlılığın pozitif değerlendirildiği durumlar, psikolojik danışmanların danışandan beklentilerini (zamanında gelme, oturumlara devamlılık, kurallara uyma vb.) en çok karşılayan grup, kişiye bağımlılığı yüksek olan danışanlar olduğu yönündedir. Diğer yandan sonlandırmayı zor kabul etme ve psikolojik danışmanlara bağımlı hale gelme gibi negatif bir durumdur (Yakın, 2014).

Tedavide dikkate alınması gereken en önemli yaklaşım tarzı doğru terapi yönteminin belirlenmesi ve kişiye özel 
süreçlerin işletilmesidir. Burada uygulanacak olan terapi yönteminin doğru farmakolojik yaklaşımlarla sentezlenmesi esastır, çünkü tedavinin başarısını etkileme potansiyeli olan değişkenlerin başında kişinin yaşam olayları, ailevi ilişkileri ve bağımlılık durumunun şiddeti gibi faktörler gelmektedir.

Diğer yandan son yapilan çalışmalar 1şığında bağımlılık konusunda diğer psikoterapi yöntemlerinden öne çıkan terapi yöntemi Bilişsel Davranışçı Terapi yönündedir (Yıldırım ve Sütçü, 2016; Bengisoy, Özdemir, Erkıvanç, Şahin, İskifoğlu, 2019). BDT'nin terapi boyunca bireylere teknikler öğretildiği için bireyler üzerindeki etkililiği kalıcı ve uzun sürmektedir.

\section{Tartışma, Sonuç ve Öneriler}

Bağımlılığın temelinde yatan psiko-dinamikler ve tetikleyiciler fizyolojik olabileceği gibi sosyal, psikolojik, davranışsal ve genetik de olabilmektedirler. Yapılan araştırmalar sonucunda elde edilen en temel bilgi bağımlılığın oluşumunda tek bir faktörün rol almadığını ancak birden fazla faktörün bir araya gelmesiyle oluştuğunu göstermektedir (Diclemente, 2016).

$\mathrm{Bu}$ araştırmada kişiye bağımlılık eğilimi çalışılarak bu konu ile ilgili yapılan makaleler incelenmiş̧ir. Özetlenecek olursa, yapılan bilimsel çalışmalara bakıldığında bağımlılık temelde bir bağlanma bozukluğu olarak görülmektedir (Pincus ve Wilson, 2001). Genel olarak güvenli bağlanma bağımlılığa karşı bir kalkan görevi görürken, güvensiz bağlanma temelde bir risk faktörü olarak açıklanmıştır (Franzblau, 1999). Kişiye bağımlılık eğilimi yüksek olan kişiler hem kendilerinde var olan potansiyelin ortaya çıkmasına engel olurlar hem de ruhsal bozuklukların ortaya çımasına zemin hazırlarlar (Franzblau, 1999). Kişiye bağımlılık diğer bağımlılık çeşitleri gibi üzerinde çalışılması gereken davranışsal bağımlılıkların içinde yer almaktadır. Kişiye bağımlılığa yönelik çalışmaların arttırılması gerekmektedir. Özellikle ülkemizde bu konuda yapılan çalışmalar oldukça azdır. Son yapılan bilimsel çalışmalara bakıldığında, BDT etkin, yönlendirici, yapılandırılmış bir terapi yöntemi olduğundan dolayı diğer terapilere kıyasla öne çıktığı yönündedir (Bengisoy, Özdemir, Erkıvanç, Şahin, İskifoğlu, 2019).

$\mathrm{Bu}$ çalışmanın bulguları alan yazından elde edilen verilerle birlikte incelendiğinde kişiye bağımlılık fenomeninin incelenmesine yönelik farklı yaklaşımlar sergilenmesi gerektiği ortaya çıkmaktadır. Öncelikle kişiye bağımlılık fenomeninin Türk kültürü için tanımlanması ve kültürlerarası tanı kriterlerinin denkliğine bakılmalıdır. Avrupa ve Amerika'da konu ile ilgili yapılmış çalışmalar incelendiğinde kişiye bağımlılık fenomeninin kültüre özgü yanlarının olabileceği anlaşılmaktadır (Sümer, Oruçlular, Çapar, 2015).

Bir diğer önemli unsur kişiye bağımlılığın gelişim evrelerini daha dikkatli ve derinlemesine inceleyerek ortaya koymaktır. Kuramsal alt yapısı güçlü bir çalışma ile belirlenecek gelişim evreleri sonraki çalışmalarda önleyici rehberlik ve ileri psiko-terapi programlarının daha iyi çalışmasına olanak sağlayacaktır.

Gelecek araştırmalarda bağlanma temelli bağımlılık müdahale programlarının geliştirilmesi alana katkıda bulunacaktır. Okullarda bu konuyla ilgili grupla ya da bireysel önleyici rehberlik çalışmaları yapılmalı ve ayrıca bilişsel davranışçı terapi teknikleri kullanılarak psikoeğitimler verilmelidir. Çeşitli yaş gruplarında çalışılması gereken bir konudur. Son yapılan çalışmalar, kültürel faktörlerin de bağımlılığın eğilimini etkilediği yönündedir.

\section{Beyannameler}

\section{Etik Onayı ve Katılım Onayı}

Yürütmüş olduğum bu çalışma literatür taraması ve derlemedir. Herhangi bir katılımcı kitlesinden veri toplanmamıştır. Dolayısı ile üniversite etik komisyonundan izin gerektirmemektedir. Ancak tüm etik kurallar alan yazın taranırken dikkate alınmıștır.

Yayın İzni

Yayın izni dergiye devredilmiştir.

\section{Veri ve Materyallerin Mevcudiyeti}

Çalışma alan yazının taranması ile oluşmuştur. Dolayısı ile herhangi bir veri kullanılmamıștır. Ancak talep edilmesi halinde taranan makaleler ibraz edilebilir.

\section{Çıkar Çatışması}

Hakemlik ve editörlük sürecinde çıkar çatışmasına mahal verecek herhangi bir durum söz konusu değildir.

\section{Finansman}

$\mathrm{Bu}$ çalıșmanın gerçekleştirilmesinde herhangi bir kuruluștan finansal destek alınmamıştır.

\section{Yazar Katkıları}

Tubanur Çelik İskifoğlu: Alan yazının taranması, değerlendirmeye alınacak kaynakların organize edilmesi ve tematik analizler yapılması gibi boyutlarda katkılar koymuştur.

Gökhan İskifoğlu: Yapılan tematik analizlerin raporlanması ve makale metnin yazılmasında katkı koymuştur.

\section{Teșekkürler}

Bu çalışmanın gerçekleşebilmesi için taramam gereken literatüre erişim sağlamamı kolaylaştıran üniversite ve veri tabanı yöneticilerine teşekkür ederim.

\section{Kaynaklar}

Ainsworth, M. D. S. (1972). Attachment and dependency: A comparison. (Ed.: J.L.Gewirtz). Attachment and Dependency, New York: Wiley

Alonso-Arbiol, I., Shaver, P. R. ve Yarnoz, S. (2002). Insecure attachment, gender roles, and interpersonal dependency in the Basque Country. Personal Relationships, 9, 479-490.

Ançel, G. (2012). Karşılıklı bağımlılık kavramı: Hemşirelikle ilişkisi ve karşılıklı bağımlılığı belirleme araçları. Hemşirelikte Araştırma Geliştirme Dergisi, 2012(1), 70-78.
Ançel, G. ve Kabakçı, E. (2009). Psychometric properties of the Turkish form of Codependency Assessment Tool. Archives of Psychiatric Nursing, 23(6), 441- 453.

Arntz, A. (2012). Schema therapy for cluster C personality disorders. The Wiley-Blackwell Handbook of Schema Therapy: Theory, Research, and Practice, 397-414.

Aydın, B. (2016). Toplumsal dışlanma ve aidiyet kıskacında bağımlı gençlik. Yüksek lisans tezi. Selçuk üniversitesi.

Baykan, N. (2014). Anne-Baba Tutumları ile İnternet Bağımlılık Düzeyi Arasındaki İlişkinin İncelenmesi (Sultanbeyli İlçesi 
Örneği). Yeditepe Üniversitesi, Eğitim Bilimleri Enstitüsü, Ĕgitim Yönetimi ve Denetimi Anabilim Dalı Yüksek Lisans Tezi, İstanbul.

Bengisoy, A., Özdemir, M.B., Erkıvanç, F., Şahin, S., İskifoğlu, T.Ç. (2019). Bilişsel davranış̧ı terapi kullanılarak yapılan araștırma makalelerinin içerik analizi 1997-2018. Türk Psikolojik Danışma ve Rehberlik Dergisi, 54(9), 745-793.

Bornstein, R. F. (1992). The dependent personality: Developmental, social and clinical perspectives. Psychological Bulletin, 112, 3-23.

Bornstein, R. F. (2005). The dependent patient: Diagnosis, assessment and treatment. Professional Psychology: Research and Practice, 36(1), 82-89

Bornstein, R. F., Krukonis, A. B., Manning, K. A., Mastrosimone, C. C. ve Rossner, S. C. (1993). Interpersonal dependency and health service utilization in a college student sample. Journal of Social and Clinical Psychology, 12, 262-279.

Bowlby, J. (1982). Attachment and loss. Vol. 1. Attachment. 2. Basım. New York: Basic Books.

Carlson, N. (2014). Fizyolojik psikoloji. 8. Baskı. Ankara: Nobel.

Dereli, E. (2018). Yetișkin bireylerde eș bağımlılık, bağlanma ve aleksitimi arasındaki ilișkinin incelenmesi (Yayımlanmamıs yüksek lisans tezi). Üsküdar Üniversitesi /Sosyal Bilimler Enstitüsü, İstanbul.

Diclemente, C.C. (2016). Bağımlılık ve değişim.1. basım. Ankara: Nobel.

Franzblau, S. H. (1999). Attachment theory. Feminism \& Psychology, SAGE 9(1), 5-9.

Havaçeliği, D. (2013). Partner ilişkilerindeki ilişki bağımlılı̆̆ının ebeveyn bağlanma stilleri ve madde kullanımı ile ilișkisi (Yayımlanmamış yüksek lisans tezi). Ege Üniversitesi/Sağlık Bilimleri Enstitüsü, İzmir.

Hirschfeld, R., Klerman, G., Gough, H., Bareett, J. ve Korchin, S. (1977). A measure of interpersonal dependency. Journal of Personality Assessment, 41(6), 610- 618.
İnanç, Y. B. ve Yerlikaya, E. E. (2008). Kișilik kuramları. Ankara: Pegem Akademi Yayınları.

Kökçü, F. ve Kesebir, S. (2010). İki uçlu olgular ve çocuklarında bağlanma biçimi'nin mizaç, kișilik ve klinik özellikler ile ilişkisi: kontrollü bir çalışma. Türk Psikiyatri Dergisi, 21, 1-10.

Lancer, D. (2018). Eş bağımlılık. 2. Basım. Nobel yayınevi.

Maslow, A. (1970). Motivation and personality. Third Edition, New York: Harper \& Row Puplishers.

Pincus, A. L. ve Wilson, K. R. (2001). Interpersonal variability in dependent personality. Journal of Personality, 69(2), 224-251.

Soylu, C. (2017). İnsana bağımlılık. 1. baskı. Ankara: Ekinoks.

Springer, C., Britt, T. ve Schlenker, B. (1998). Codependency: Clarifying the construct. Journal of Mental Health Counseling, 20(2), 141-166.

Sümer, N., Oruçlular, Y., Çapar, T. (2015). Bağlanma ve bağımlılık. Bağımlılık Dergisi, 16(4),192-209.

Şenormanc1, Ö., Konkan, R., Sungur, M. Z. (2010). İnternet bağımlılığı ve bilișsel davranıșçı terapi. Anadolu Psikiyatri Dergisi. 11, 261-268

Tarhan, N., Nurmedov, S. (2019). Bağımlılık. 7. Baskı. Ankara: Timaş Yayınları.

Ulusoy, Y. (2010). Kişiler Arası Bağımlılık Ölçeğinin (Interpersonal Dependency Inventory) uyarlama çalısması. Yüksek Lisans Tezi, Çukurova Üniversitesi Sosyal Bilimler Enstitüsü, Adana.

Yakın, D. (2014). Bağımlı kișilik örüntüsü ve terapötik iș birliğii: Şema odaklı bilişsel davranışçı terapi uygulaması. Ayna Klinik Psikoloji Dergisi. 1(2),1-13.

Yıldırım, Z. E.; Sütçü, S.T. (2016). Madde ile ilișkili bozuklukların tedavisinde bilişsel davranışçı grup terapisi etkililiği: sistematik bir gözden geçirme. Psikiyatride Güncel Yaklaşımlar 8(1), 108-128.

Wells, M. C., Hill, M. B., Brack, G., Brack, C. J. ve Firestone, E. E. (2006). Codependency's relationship to defining characteristics in college students. Journal of College Student Psychotherapy, 20(4), 71-84. 